\title{
Medial temporal tau can be a predictor for amyloid- $B$ positivity in mild cognitive impairment
}

Hanna Cho

Yonsei University College of Medicine

Min Seok Baek

Yonsei University College of Medicine

Hye Sun Lee

Yonsei University College of Medicine

Jae Yong Choi

Yonsei University College of Medicine

Jae Hoon Lee

Yonsei University College of Medicine

Young Hoon Ryu

Yonsei University College of Medicine

Myung Sik Lee

Yonsei University College of Medicine

Chul Hyoung Lyoo ( $\square$ lyoochel@yuhs.ac)

Gangnam Severance Hospital https://orcid.org/0000-0003-2231-672X

\section{Research}

Keywords: Alzheimer's disease (26), mild cognitive impairment (39), PET (122), amyloid, tau

Posted Date: March 5th, 2020

DOI: https://doi.org/10.21203/rs.3.rs-16213/v1

License: (c) (i) This work is licensed under a Creative Commons Attribution 4.0 International License.

Read Full License 


\section{Abstract}

Introduction Although both amyloid- $-(A ß)$ and tau positron emission tomography (PET) are important for the assessment of Alzheimer's disease pathology, obtaining two PET scans can be challenging in clinical practice. We sought to determine whether $\mathrm{A}$-positivity in $\mathrm{MCl}$ patients can be predicted with only a single tau PET scan.

Methods We prospectively recruited $105 \mathrm{MCl}$ patients and performed two PET scans with $18 \mathrm{~F}$ florbetaben and 18 F-flortaucipir with all patients. Regional 18 F-flortaucipir standardized uptake value ratios (SUVR) were measured using FreeSurfer-generated volumes-of-interest and with the cerebellar crus median as a reference.

Results We classified 49 (46.7\%) MCl patients as Aß-positive using visual assessment. In 12 regions showing greater tau uptake in the $\mathrm{MCl}-\mathrm{A} \beta+$ patients compared to the $\mathrm{MCl}-\mathrm{A} \beta$ - patients, tau uptake in the entorhinal cortex showed the greatest area under the curve (AUC) value (AUC $=0.835$, sensitivity/specificity $=73.5 \% / 85.7 \%$ ) for discriminating Aß-positivity. The second and third largest AUCs were obtained with tau uptake in the amygdala $(A U C=0.814$, sensitivity $/$ specificity $=65.3 \% / 94.6 \%$ ) and the parahippocampal cortex (AUC $=0.802$, sensitivity $/$ specificity $=67.4 \% / 91.1 \%$ ). However, post-hoc analyses revealed no statistical differences between the three regions.

Conclusions Single tau PET scans may be helpful in the evaluation of disease state and stage at the same time in $\mathrm{MCl}$ patients.

\section{Background}

Amyloid- $\beta(A ß)$ and tau are important biomarkers for the evaluation of Alzheimer's disease (AD) state and stage particularly in the early stage [1]. Aß-positive mild cognitive impairment $(\mathrm{MCl})$ is considered to be the prodromal, or earliest stage of AD [2]. Previous amyloid positron emission tomography (PET) studies have demonstrated that 40 to $60 \%$ of $\mathrm{MCl}$ patients are Aß-positive and Aß-positivity on PET (PET-Aßpositivity) is highly correlated with clinical progression from $\mathrm{MCl}$ to dementia. [1] Meanwhile, tau PET visualizes distinct topographical distribution patterns of neurofibrillary tangles (NFT), thereby reflecting the clinical and pathological severity of $A D$ [3]. Tau first accumulates in the entorhinal cortex and spreads dorsally toward the neocortex, while tau accumulation beyond the medial temporal regions occurs almost exclusively in Aß-positive patients. As expected due to this distinct spreading pattern, tau accumulation has been found predominantly in the medial and basal temporal regions in $\mathrm{A}$-positive $\mathrm{MCl}$ patients in previous tau PET studies $[4,5]$.

Although these two imaging biomarkers provide complementary information, it can be challenging to obtain both PET images in clinical practice. Moreover, Aß-positivity is significantly more important for $\mathrm{MCl}$ patients than clinical AD patients who typically show up to $90 \%$ of Aß-positivity [6]. In this study, we sought to determine whether PET-Aß-positivity can be predicted with only a single tau PET scan, and which region may be the most predictive of PET-Aß-positivity in $\mathrm{MCI}$ patients. 


\section{Methods}

\section{Participants}

From January 2015 to August 2017, we prospectively included $105 \mathrm{MCl}$ patients at the Memory Disorder Clinic of Gangnam Severance Hospital. All MCl patients were diagnosed using Petersen's criteria [7]. All participants underwent clinical interviews, a neuropsychological test battery, genotyping for apolipoprotein $\mathrm{E}(\mathrm{ApoE})$, brain magnetic resonance (MR) imaging, and two PET scans with ${ }^{18} \mathrm{~F}$ florbetaben (for $A ß$ ) and ${ }^{18} \mathrm{~F}$-flortaucipir (for tau). PET-Aß-positivity was determined by consensus between two nuclear medicine specialists using a validated visual assessment method $[8,9]$, and the $\mathrm{MCl}$ patients were dichotomized into two groups based on PET-Aß-positivity ( $\mathrm{MCl}-\mathrm{A} \beta+$ and $\mathrm{MCl}-\mathrm{A} \beta-$ ). This study was approved by the Institutional Review Board of Gangnam Severance Hospital and written informed consent was obtained from all subjects.

\section{Image processing steps}

We used the Freesurfer 5.3 software (Massachusetts General Hospital, Harvard Medical School; http://surfer.nmr.mgh.harvard.edu) to create participant-specific volume-of-interest (VOI) images. In brief, T1-weighted MR images were first resliced to FreeSurfer space $(256 \times 256 \times 256$ matrix with $1 \mathrm{~mm}$ isovoxels), segmented into gray and white matter, and their 3D-surfaces were reconstructed. Cortical regions were segmented with the curvature information of the white matter surface, and subcortical regions with the probabilistic registration technique. Finally, participant-specific composite VOI mask images for 20 cortical and subcortical regions were created after merging anatomically-related regions.

Statistical parametric mapping 12 (SPM12; Wellcome Trust Centre for Neuroimaging, London, UK) and inhouse software implemented in MATLAB 2015b (MathWorks, Natick, MA, USA) were used for integrative analysis of the PET and MR images. PET images were first co-registered to individual MR images in FreeSurfer space and regional standardized uptake value ratio (SUVR) images were created using the cerebellar crus median obtained from spatially-normalized PET images. Finally, regional SUVR values were measured by overlaying the participant-specific VOI mask images on individual SUVR images.

\section{Statistical analysis}

Statistical analyses were performed with SPSS 23 (IBM Corp., Armonk, NY, USA) and MedCalc for Windows, version 18.1 (MedCalc Software, Ostend, Belgium). Demographic data and neuropsychological tests were compared between the $\mathrm{MCl}-\mathrm{A} \beta+$ and $\mathrm{MCl}-\mathrm{A} \beta$ - groups with independent t-test for continuous variables or Chi-square test for categorical variables. Independent t-test was used for unadjusted comparisons of regional ${ }^{18} \mathrm{~F}$-flortaucipir uptake between the $\mathrm{MCl}-\mathrm{A} \beta+$ and $\mathrm{MCl}-\mathrm{A} \beta$ - groups, and multivariate logistic regression analysis was used to evaluate independent associations between the 
regional ${ }^{18} \mathrm{~F}$-flortaucipir uptake and PET-Aß-positivity after adjusting for age, education, sex, duration, and ApoE $\varepsilon 4$ genotype. We excluded the hippocampus due to the effects of off-target binding of ${ }^{18} \mathrm{~F}$ flortaucipir to the choroid plexus. [10] By using the receiver-operating characteristic (ROC) analysis, the accuracy of tau PET to discriminate PET Aß-positivity was then assessed for the regions showing statistically significant differences between the $\mathrm{MCl}-\mathrm{A} \beta+$ and $\mathrm{MCl}-\mathrm{A} \beta$ - groups (unadjusted- $P<0.05$ ). Comparisons of area under the ROC curves (AUC) was performed using the DeLong method. Youden's method was used to identify an optimal cut-off point on the ROC curves to maximize the sensitivity and specificity of tau uptake in each region.

\section{Results}

Of the $105 \mathrm{MCl}$ patients, 49 (46.7\%) were $A ß+$ on visual assessment. Detailed demographic characteristics are shown in Table 1.

To determine which region is most suitable for PET-Aß-positivity screening, we first compared regional ${ }^{18} \mathrm{~F}$-flortaucipir uptake between the $\mathrm{MCl}-\mathrm{A} \beta+$ and $\mathrm{MCl}-\mathrm{A} \beta$ - patients. The $\mathrm{MCl}-\mathrm{A} \beta+$ patients showed greater

${ }^{18} \mathrm{~F}$-flortaucipir uptake in most of the cortical regions except the sensorimotor and anterior cingulate cortices, most prominently in the inferior parietal and lateral and medial temporal cortices when compared to $\mathrm{MCl}-\mathrm{A} \beta$ - patients (Table 2). The results of multivariate logistic regression analysis adjusted for demographic variables were almost consistent with the unadjusted results (Table 2).

Of the 12 tau uptake regions with significant differences between the $\mathrm{MCl}-\mathrm{A} \beta+$ and $\mathrm{MCl}-\mathrm{A} \beta$ - patients, the entorhinal cortex showed the greatest AUC value (AUC $=0.835$ ) with a sensitivity of $73.5 \%$ and specificity of $85.7 \%$. The second and third greatest AUCs were obtained in the amygdala (AUC $=0.814$ ) with a sensitivity of $65.3 \%$ and specificity of $94.6 \%$, as well as the parahippocampal cortex (AUC $=0.802$ ) with a sensitivity of $67.4 \%$ and specificity of $91.1 \%$. However, post-hoc analyses of the AUC revealed that there were no statistical differences between the entorhinal cortex and amygdala or parahippocampal cortex using DeLong's method (Table 3).

\section{Discussion}

In this study, we found that ${ }^{18} \mathrm{~F}$-flortaucipir uptake in the entorhinal cortex was the best predictor for discriminating PET-Aß-positivity, and those in the amygdala or parahippocampal cortex also showed similar accuracy. This suggests that tau PET can serve as a predictor for PET-Aß-positivity in $\mathrm{MCl}$ patients.

For predicting PET-Aß-positivity in $\mathrm{MCl}$, several clinical or MR-based methods have been developed, including the use of nomograms based on neuropsychological tests [11], informant-based reporting of cognitive symptoms [12], and MR-based brain morphometry or hippocampal volumetry [13]. However, while morphometry which provided up to $80 \%$ of the sensitivity and specificity for predicting PET-Aßpositivity without clinical variables, other methods were suboptimal. Cerebrospinal fluid (CSF) $A ß$ is also 
a powerful biomarker for predicting $A ß$ pathology in $A D$ [14]. Previous studies have consistently shown a negative relationship between the CSF $A \beta_{42}$ or $A \beta_{42} / A \beta_{40}$ ratio and $A \beta$ burden measured by PET and high agreement in Aß-positivity status between CSF studies and amyloid PET [14-17]. Nevertheless, the invasiveness required to obtain CSF limits its usage in clinical practice.

Like the previous ${ }^{18} \mathrm{~F}$-flortaucipir studies that showed greater uptake in the medial and inferior temporal regions in $\mathrm{MCl}$ patients when compared to healthy controls $[4,5,18]$, the $\mathrm{MCl}-\mathrm{A} \beta+$ patients in our study showed greater ${ }^{18} \mathrm{~F}$-flortaucipir uptake in the parietal, lateral and medial temporal regions when compared to the $\mathrm{MCl}-\mathrm{A} \beta$ - patients. ${ }^{18} \mathrm{~F}$-flortaucipir uptake in these regions was also useful for discriminating $\mathrm{AD}$ from other neurodegenerative diseases. ${ }^{14}$ We therefore believe it is reasonable to select an optimal area from the regions with greater uptake in $\mathrm{MCl}-\mathrm{A} \beta+$ patients for predicting PET A $\beta$-positivity.

In our study, the highest sensitivity was achieved with ${ }^{18} \mathrm{~F}$-flortaucipir uptake in the entorhinal $(73.5 \%)$ and parahippocampal (67.4\%) cortices, as expected by the early appearance of NFT pathology in these regions in $A D$ [19]. Expansion of $A \beta$ throughout the neocortex without tau burden in the entorhinal cortex sufficient to exceed the cut-off threshold in ${ }^{18} \mathrm{~F}$-flortaucipir PET might reduce the sensitivity. Similarly, ${ }^{18} \mathrm{~F}$ flortaucipir uptake in the entorhinal, amygdala and parahippocampal cortices provided 85.7 to $94.6 \%$ of the specificity. Small false positivity for predicting PET-Aß-positivity might be attributable to primary agerelated tauopathy (PART) [20]. However, there was no interaction between age and ${ }^{18} \mathrm{~F}$-flortaucipir uptake in the entorhinal and parahippocampal cortices.

Although the greatest AUC value was achieved with the entorhinal cortex, followed by the amygdala and parahippocampal cortex, the post-hoc comparison of AUC values between the entorhinal cortex and the other two regions did not exhibit superiority of one region over any others for predicting PET-Aß-positivity. However, compared to the entorhinal cortex, the amygdala and parahippocampal cortex provided lower sensitivity $(<70 \%)$ and higher specificity $(>90 \%)$. When focusing on the screening of PET-Aß-positivity, the entorhinal cortex may be the best region for predicting PET-Aß-positivity.

This study was limited by the visual assessment for deciding A $\beta$-positivity, although this has been validated [9]. In addition, absence of an external validation can be a limitation. Nevertheless, our study first added the usefulness of tau PET for predicting PET-Aß-positivity in $\mathrm{MCl}$ patients.

\section{Conclusions}

In conclusion, ${ }^{18} \mathrm{~F}$-flortaucipir uptake in the medial temporal regions may be used to predict PET-Aßpositivity in $\mathrm{MCl}$ patients without considering clinical information. Single tau PET scans may be helpful for discriminating $A ß$-positivity with uptake in the medial temporal regions as well as for monitoring the disease progression in $\mathrm{MCl}$ patients.

\section{References}


1. Jack CR, Jr., Wiste HJ, Vemuri P, Weigand SD, Senjem ML, Zeng G, et al. Brain beta-amyloid measures and magnetic resonance imaging atrophy both predict time-to-progression from mild cognitive impairment to Alzheimer's disease. Brain. 2010;133(11):3336-48. doi: 10.1093/brain/awq277. Epub 2010 Oct 8.

2. Wolk DA, Price JC, Saxton JA, Snitz BE, James JA, Lopez OL, et al. Amyloid imaging in mild cognitive impairment subtypes. Ann Neurol. 2009;65(5):557-68. doi: 10.1002/ana.21598.

3. Cho H, Choi JY, Hwang MS, Kim YJ, Lee HM, Lee HS, et al. In vivo cortical spreading pattern of tau and amyloid in the Alzheimer disease spectrum. Ann Neurol. 2016;80(2):247-58. doi: 10.1002/ana.24711. Epub 2016 Jul 8.

4. Johnson KA, Schultz A, Betensky RA, Becker JA, Sepulcre J, Rentz D, et al. Tau positron emission tomographic imaging in aging and early Alzheimer disease. Ann Neurol. 2016;79(1):110-9.

5. Ossenkoppele R, Rabinovici GD, Smith R, Cho H, Scholl M, Strandberg O, et al. Discriminative Accuracy of [18F]flortaucipir Positron Emission Tomography for Alzheimer Disease vs Other Neurodegenerative Disorders. Jama. 2018;320(11):1151-62.

6. Ossenkoppele R, Jansen WJ, Rabinovici GD, Knol DL, van der Flier WM, van Berckel BN, et al. Prevalence of amyloid PET positivity in dementia syndromes: a meta-analysis. Jama. 2015;313(19):1939-49.

7. Petersen RC, Smith GE, Waring SC, Ivnik RJ, Tangalos EG, Kokmen E. Mild cognitive impairment: clinical characterization and outcome. Arch Neurol. 1999;56(3):303-8.

8. Sabri O, Sabbagh MN, Seibyl J, Barthel H, Akatsu H, Ouchi Y, et al. Florbetaben PET imaging to detect amyloid beta plaques in Alzheimer's disease: phase 3 study. Alzheimers Dement. 2015;11(8):964-74.

9. Villemagne VL, Ong K, Mulligan RS, Holl G, Pejoska S, Jones G, et al. Amyloid imaging with (18)Fflorbetaben in Alzheimer disease and other dementias. J Nucl Med. 2011;52(8):1210-7.

10. Marquie M, Normandin MD, Vanderburg CR, Costantino IM, Bien EA, Rycyna LG, et al. Validating novel tau positron emission tomography tracer [F-18]-AV-1451 (T807) on postmortem brain tissue. Ann Neurol. 2015;78(5):787-800.

11. Tomadesso C, Gonneaud J, Egret S, Perrotin A, Pelerin A, de Flores R, et al. Is there a specific memory signature associated with Abeta-PET positivity in patients with amnestic mild cognitive impairment? Neurobiol Aging. 2019;77:94-103.(doi):10.1016/j.neurobiolaging.2019.01.017. Epub Jan 31.

12. Brunet HE, Miller JB, Shi J, Chung B, Munter BT, Sabbagh MN. Does informant-based reporting of cognitive symptoms predict amyloid positivity on positron emission tomography? Alzheimers Dement (Amst). 2019;11:424-429.(doi):10.1016/j.dadm.2019.04.004. eCollection Dec.

13. Huijbers W, Mormino EC, Schultz AP, Wigman S, Ward AM, Larvie M, et al. Amyloid-beta deposition in mild cognitive impairment is associated with increased hippocampal activity, atrophy and clinical progression. Brain. 2015;138(Pt 4):1023-35. doi: 10.93/brain/awv007. Epub 2015 Feb 11.

14. Hake A, Trzepacz PT, Wang S, Yu P, Case M, Hochstetler H, et al. Florbetapir positron emission tomography and cerebrospinal fluid biomarkers. Alzheimers Dement. 2015;11(8):986-93. 
15. Ewers M, Insel P, Jagust WJ, Shaw L, Trojanowski JQ, Aisen P, et al. CSF biomarker and PIB-PETderived beta-amyloid signature predicts metabolic, gray matter, and cognitive changes in nondemented subjects. Cereb Cortex. 2012;22(9):1993-2004. doi: 10.1093/cercor/bhr271. Epub 2011 Oct 29.

16. Fagan AM, Mintun MA, Mach RH, Lee SY, Dence CS, Shah AR, et al. Inverse relation between in vivo amyloid imaging load and cerebrospinal fluid Abeta42 in humans. Ann Neurol. 2006;59(3):512-9. doi: 10.1002/ana.20730.

17. Landau SM, Lu M, Joshi AD, Pontecorvo M, Mintun MA, Trojanowski JQ, et al. Comparing positron emission tomography imaging and cerebrospinal fluid measurements of beta-amyloid. Ann Neurol. 2013;74(6):826-36. doi: 10.1002/ana.23908.

18. Cho H, Choi JY, Hwang MS, Lee JH, Kim YJ, Lee HM, et al. Tau PET in Alzheimer disease and mild cognitive impairment. Neurology. 2016;87(4):375-83. doi: 10.1212/WNL.0000000000002892. Epub 2016 Jun 29.

19. Braak H, Braak E. Neuropathological stageing of Alzheimer-related changes. Acta Neuropathol. 1991;82(4):239-59.

20. Crary JF, Trojanowski JQ, Schneider JA, Abisambra JF, Abner EL, Alafuzoff I, et al. Primary agerelated tauopathy (PART): a common pathology associated with human aging. Acta Neuropathol. 2014;128(6):755-66.

\section{Tables}

Table 1. Demographic characteristics of the study participants

\begin{tabular}{|c|c|c|c|}
\hline & Total MCI & MCI-AB- & MCI-AB+ \\
\hline$n$ & 105 & 56 & 49 \\
\hline Age (years) & $71.1 \pm 9.1$ & $68.9 \pm 9.7$ & $73.7 \pm 7.6^{*}$ \\
\hline $\operatorname{Sex}(M: F)$ & $41: 64$ & $17: 39$ & $24: 25$ \\
\hline Education (years) & $11.2 \pm 4.5$ & $11.0 \pm 4.3$ & $11.4 \pm 4.7$ \\
\hline Duration (years) & $2.3 \pm 1.3$ & $2.0 \pm 1.2$ & $2.6 \pm 1.3^{*}$ \\
\hline ApoE $\varepsilon 4+$ & $30(29 \%)$ & $7(13 \%)$ & $23(47 \%)^{*}$ \\
\hline MMSE & $25.7 \pm 2.7$ & $26.2 \pm 2.1$ & $25.1 \pm 3.2^{*}$ \\
\hline CDR-SB & $1.5 \pm 1.0$ & $1.3 \pm 1.0$ & $1.8 \pm 0.9^{*}$ \\
\hline \multicolumn{4}{|c|}{${ }^{18}$ F-flortaucipir SUVR $1.21 \pm 0.151 .16 \pm 0.091 .27 \pm 0.19 *$} \\
\hline \multicolumn{4}{|c|}{${ }^{18}{ }_{\text {F-florbetaben SUVR }} 1.62 \pm 0.311 .38 \pm 0.081 .89 \pm 0.26^{*}$} \\
\hline
\end{tabular}

Data are presented as mean $\pm \mathrm{SD} .{ }^{*} P<0.05$ for the comparisons between MCI-A $\beta$ - and MCI-A $\beta+$ groups 
Abbreviations: $\mathrm{MCI}=$ mild cognitive impairment, $\mathrm{A} \beta+/-=$ amyloid-positivity, $\mathrm{ApoE}=$ apolipoprotein E, MMSE = Mini-Mental State Examination, CDR-SB = Clinical Dementia Rating sum-of-boxes

Table 2. Comparison of ${ }^{18}$ F-flortaucipir binding values and multiple logistic regression associated with amyloid positivity in MCI

\begin{tabular}{|c|c|c|c|}
\hline & Unadjusted $^{\mathrm{a}}$ & \multicolumn{2}{|l|}{ Adjusted $^{\mathrm{b}}$} \\
\hline & MCI-A $\beta-$ MCI-A $\beta+P$-value & $O R^{\mathrm{C}}(95 \% C I)$ & $P$-value \\
\hline Prefrontal & $1.20 \pm 0.091 .26 \pm 0.18 \quad 0.028$ & $1.461(0.992-2.151)$ & 0.055 \\
\hline Sensorimotor & $1.08 \pm 0.091 .10 \pm 0.14 \quad 0.475$ & $1.218(0.801-1.854)$ & 0.356 \\
\hline Superior parietal & $1.09 \pm 0.101 .17 \pm 0.21 \quad 0.013$ & $1.466(1.038-2.071)$ & 0.030 \\
\hline Inferior parietal & $1.14 \pm 0.111 .28 \pm 0.26<0.001$ & $1.620(1.149-2.286)$ & 0.006 \\
\hline Precuneus & $1.20 \pm 0.101 .31 \pm 0.250 .004$ & $1.517(1.056-2.178)$ & 0.024 \\
\hline Occipital & $1.14 \pm 0.081 .21 \pm 0.20 \quad 0.010$ & $1.456(0.976-2.174)$ & 0.066 \\
\hline Superior temporal & $1.10 \pm 0.091 .21 \pm 0.19<0.001$ & $1.908(1.231-2.956)$ & 0.004 \\
\hline Middle temporal & $1.18 \pm 0.091 .42 \pm 0.31<0.001$ & $2.177(1.427-3.321)$ & $<0.001$ \\
\hline Inferior temporal & $1.21 \pm 0.091 .46 \pm 0.30<0.001$ & $2.076(1.389-3.102$ & $<0.001$ \\
\hline Entorhinal & $1.27 \pm 0.171 .72 \pm 0.40<0.001$ & $1.856(1.374-2.508$ & $<0.001$ \\
\hline Parahippocampal & $1.20 \pm 0.111 .48 \pm 0.29<0.001$ & $1.953(1.394-2.735$ & $<0.001$ \\
\hline Amygdala & $1.32 \pm 0.141 .72 \pm 0.41<0.001$ & $1.629(1.251-2.121)$ & $<0.001$ \\
\hline Anterior cingulate & $1.23 \pm 0.101 .28 \pm 0.150 .081$ & $1.429(0.975-2.093)$ & 0.067 \\
\hline Posterior cingulate & $1.23 \pm 0.101 .35 \pm 0.250 .001$ & $1.606(1.137-2.268)$ & 0.007 \\
\hline
\end{tabular}

$\mathrm{a}_{\text {Data are presented as mean } \pm \mathrm{SD} .}{ }^{\mathrm{b}}$ Adjusted for age, education, sex, disease duration, and ApoE $\varepsilon 4$ genotype. ${ }^{\mathrm{C}} \mathrm{OR}$ was analysed by regional SUVR per 0.1 units.

Abbreviations: $\mathrm{MCI}=$ mild cognitive impairment, $\mathrm{A} \beta+/-=$ amyloid-positivity, $\mathrm{OR}=$ odds ratio, $\mathrm{CI}=$ confidence interval

Table 3. Comparison of AUC values between entorhinal and other regional tau uptake and determination of optimal cut-off point in MCI 


\begin{tabular}{|c|c|c|c|c|c|c|}
\hline & $A U C(95 \% C I)$ & $P$-value* & $\begin{array}{c}P- \\
\text { value }^{* *}\end{array}$ & $\begin{array}{l}\text { cut- } \\
\text { off }^{++}\end{array}$ & $\begin{array}{c}\text { Sensitivity (\%) } \\
(95 \% \mathrm{CI})\end{array}$ & $\begin{array}{c}\text { Specificity (\%) } \\
(95 \% \mathrm{CI})\end{array}$ \\
\hline Prefrontal & $\begin{array}{l}0.611(0.499 \\
-0.723)\end{array}$ & 0.050 & $\stackrel{<}{0.001}$ & 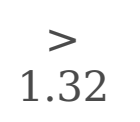 & $\begin{array}{c}30.6 \\
(18.3-45.4)\end{array}$ & $\begin{array}{c}94.6 \\
(85.1-98.9)\end{array}$ \\
\hline Superior parietal & $\begin{array}{l}0.574(0.459 \\
-0.689)\end{array}$ & 0.192 & $\begin{array}{c}< \\
0.001\end{array}$ & $\begin{array}{c}> \\
1.26\end{array}$ & $\begin{array}{c}32.7 \\
(19.9-47.5)\end{array}$ & $\begin{array}{c}94.6 \\
(85.1-98.9)\end{array}$ \\
\hline Inferior parietal & $\begin{array}{c}0.650(0.540 \\
-0.760)\end{array}$ & 0.008 & $\begin{array}{c}< \\
0.001\end{array}$ & ${ }_{1.31}^{>}$ & $\begin{array}{c}42.9 \\
(28.8-57.8)\end{array}$ & $\begin{array}{c}94.6 \\
(85.1-98.9)\end{array}$ \\
\hline Precuneus & $\begin{array}{c}0.610(0.497 \\
-0.723)\end{array}$ & 0.052 & $\stackrel{<}{0.001}$ & $\begin{array}{l}> \\
1.29\end{array}$ & $\begin{array}{c}46.9 \\
(32.5-61.7)\end{array}$ & $\begin{array}{c}85.7 \\
(73.8-93.6)\end{array}$ \\
\hline Occipital & $\begin{array}{l}0.607(0.493 \\
-0.722)\end{array}$ & 0.059 & $\begin{array}{c}< \\
0.001\end{array}$ & $\begin{array}{l}> \\
1.23\end{array}$ & $\begin{array}{c}40.8 \\
(27.0-55.8)\end{array}$ & $\begin{array}{c}92.9 \\
(82.7-98.0)\end{array}$ \\
\hline $\begin{array}{l}\text { Superior } \\
\text { temporal }\end{array}$ & $\begin{array}{c}0.686(0.580 \\
-0.792)\end{array}$ & 0.001 & $\stackrel{<}{0.001}$ & $\begin{array}{l}> \\
1.22\end{array}$ & $\begin{array}{c}45.5 \\
(30.4-61.2)\end{array}$ & $\begin{array}{c}94.3 \\
(82.7-99.4)\end{array}$ \\
\hline Middle temporal & $\begin{array}{c}0.778(0.681 \\
-0.875)\end{array}$ & $\begin{array}{c}< \\
0.001\end{array}$ & 0.060 & $\stackrel{>}{1.30}$ & $\begin{array}{c}63.6 \\
(47.8-77.6)\end{array}$ & $\begin{array}{c}94.3 \\
(82.7-99.4)\end{array}$ \\
\hline Inferior temporal & $\begin{array}{c}0.786(0.692 \\
-0.881)\end{array}$ & $\begin{array}{c}< \\
0.001\end{array}$ & 0.056 & $\stackrel{>}{1.31}$ & $\begin{array}{c}65.3 \\
(50.4-78.3)\end{array}$ & $\begin{array}{c}91.1 \\
(80.4-97.0)\end{array}$ \\
\hline Entorhinal & $\begin{array}{c}0.835(0.752 \\
-0.918)\end{array}$ & $\begin{array}{c}< \\
0.001\end{array}$ & - & $\overrightarrow{1.41}$ & $\begin{array}{c}73.5 \\
(58.9-85.1)\end{array}$ & $\begin{array}{c}85.7 \\
(73.8-93.6)\end{array}$ \\
\hline Parahippocampal & $\begin{array}{c}0.802(0.709 \\
-0.896)\end{array}$ & $\begin{array}{c}< \\
0.001\end{array}$ & 0.076 & $\begin{array}{l}> \\
1.32\end{array}$ & $\begin{array}{c}67.4 \\
(52.5-80.1)\end{array}$ & $\begin{array}{c}91.1 \\
(80.4-97.0)\end{array}$ \\
\hline Amygdala & $\begin{array}{l}0.814(0.725 \\
-0.904)\end{array}$ & $\begin{array}{c}< \\
0.001\end{array}$ & 0.222 & $\overrightarrow{1.51}$ & $\begin{array}{c}65.3 \\
(50.4-78.3)\end{array}$ & $\begin{array}{c}94.6 \\
(85.1-98.9)\end{array}$ \\
\hline $\begin{array}{l}\text { Posterior } \\
\text { cingulate }\end{array}$ & $\begin{array}{l}0.641(0.530 \\
-0.752)\end{array}$ & 0.013 & $\begin{array}{c}< \\
0.001\end{array}$ & $\begin{array}{l}> \\
1.32\end{array}$ & $\begin{array}{c}49.0 \\
(34.4-63.7)\end{array}$ & $\begin{array}{c}85.7 \\
(73.8-93.6)\end{array}$ \\
\hline \multicolumn{7}{|c|}{$\begin{array}{l}{ }^{*} P \text {-value for the comparison of AUC between each region and } 0.5 \text { for null hypo } \\
\text { value for comparison of AUC between each region and the entorhinal cortex }\end{array}$} \\
\hline \multicolumn{7}{|c|}{ Abbreviations: $\mathrm{MCI}=$ mild cognitive impairment, $\mathrm{AUC}=$ area under the curve } \\
\hline
\end{tabular}

Ethics approval and consent to participate 
This study was approved by the Institutional Review Board of Gangnam Severance Hospital (IRB-No 32014-0286).

\section{Consent for publication}

Not applicable.

\section{Availability of data and materials}

The data that support the findings of this study are available on request from the corresponding author. The data are not publicly available due to privacy restriction.

\section{Competing interests}

The authors declare that they have no competing interests.

\section{Acknowledgements}

We express our special appreciation to Tae Ho Song and Won Taek Lee (PET technologists) who managed all PET scans with enthusiasm.

\section{Authors' contribution}

$\mathrm{HC}$ contributed to conceptualization of the study, collection and assembly of data, data analysis and drafting. MSB contributed to data analysis, interpretation of data, and critical revision of the manuscript for important intellectual content. HSL, JYC, JHL, and YHR contributed to collection and assembly of data, statistical analyses, and interpretation of data. $\mathrm{CHL}$ contributed to the conceptualization of the study, interpretation of data, critical revision of the manuscript for important intellectual content, and supervision. All authors read and approved the final manuscript.

\section{Funding}

This research was supported by a faculty research grant of Yonsei University College of Medicine for (62018-0068), Basic Science Research Program through the National Research Foundation of Korea (NRF) 
funded by the Ministry of Science, ICT \& Future Planning (NRF-2017R1A2B2006694) and the Ministry of Education (NRF-2018R1D1A1B07049386), and a grant of the Korea Health Technology R\&D Project through the Korea Health Industry Development Institute (KHIDI) funded by the Ministry of Health \& Welfare, Republic of Korea (grant number : HI18C1159). 